\title{
Cell Polarity as the "Logos" of Morphogenesis
}

\author{
Singo Nakazawa
}

Shimogawara 476-3, Higashiyama, Kyoto, 605, Japan

Acrepted March 22, 1988

The idea of polarity in organism can be traced back to simple experiments of inverted plants carried out by old Greek botanists such as Theophrastus who lived before Christ (Vöchting 1878). Later, the term polarity (Polarität) was actually used by Wolfgang von Goethe (1827) for a supposed fundamental principle underlying natural phenomena including organisms. Similarly, it was also used by Herbert Spencer (1875) as a common feature of developing organisms. Their polarity conception, however, was mostly philosophical rather than scientific. The scientific term "polarity" was for the first time introduced in biology by the English zoologist George Allman (1864) for explanation of the regeneration of Tubularia, a marine hydrozoan. In his report is written it as follows: "There is thus manifested in the formative force of the Tubularia-stem a well-marked polarity, which is rendered very apparently if a segment be cut out from the centre of the stem" (p. 392). The second person who noticed polarity was the German botanist Hermann Vöchting $(1878,1884)$, who observed that the cut twig of willows, e.g. Salix viminalis, formed adventitious roots always at the originally basal end, while the bud elongation always did occur toward the originally apical end regardless of the direction in which the twig was placed. In page 18 of his report (1884) is seen the following sentence: "Die polaren Kräfte, welche den Gegensatz zwischen Spitzen und Basis bedingten, äussern sich an allen Enden, die in dem System vorhanden sind."

Later, the polarity was studied in various plants and animals. Finally it was confirmed also in unicellular developing systems such as sea urchin eggs, frog eggs, fern spores, algal eggs etc. Modernized experiments were carried out by a number of biologists and many reports were published. Some comprehensive reviews of the polarity research were written by Bloch (1943, 1965), Child (1941), Wettstein (1965), Bünning (1969), etc.

The author studied experimentally the polarity in development of fern gametophytes, algal eggs and thalli, and published some critical reports (Nakazawa 1958b, 1960, 1961a, 1972, 1983). Through the experiments of his own with examination of reports by other persons, the author has the opinion that the cell polarity is a non-specific property, which is an initiator as well as a leading principle of morphogenesis, as described below.

\section{Definition}

The term polarity is defined as follows. If a certain character, visible or invisible, occurs in a space of an organic body not uniformly but having a tendency to be restricted toward a definite orientation, we consider that there is polarity in appearance of that character in the space with respect to the polarity axis of that direction. For instance, in case of Vöchting's (1878) willow twigs, the adventitious root appears always toward the basal end, so that there is polarity in root formation with respect to the longitudinal axis of the twig. In planarians, as is well-known, a piece of the body, cut on both sides transversely, usually regenerates the new head at the originally anterior end and the new tail at the opposite. A number of similar phenomena are reported.

The same definition is geometrically described as follows. In the body find the region, $A$, where a certain character appears most frequently, and the opposite region, B, where it appears in the least frequency, and draw line connecting those two regions, A and B, then it 
represents the polarity axis showing polarity as to appearance of that character (Fig. 1). It is convenient to draw the axis with an arrow whose head being the pole where the character appears at the highest frequency.

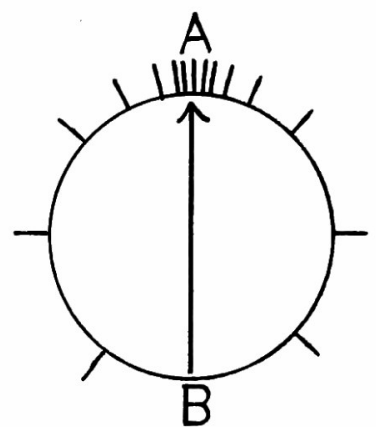

Fig. 1. Schematic illustration of a geometric definition of cell polarity. The polarity axis is shown with the arrow.
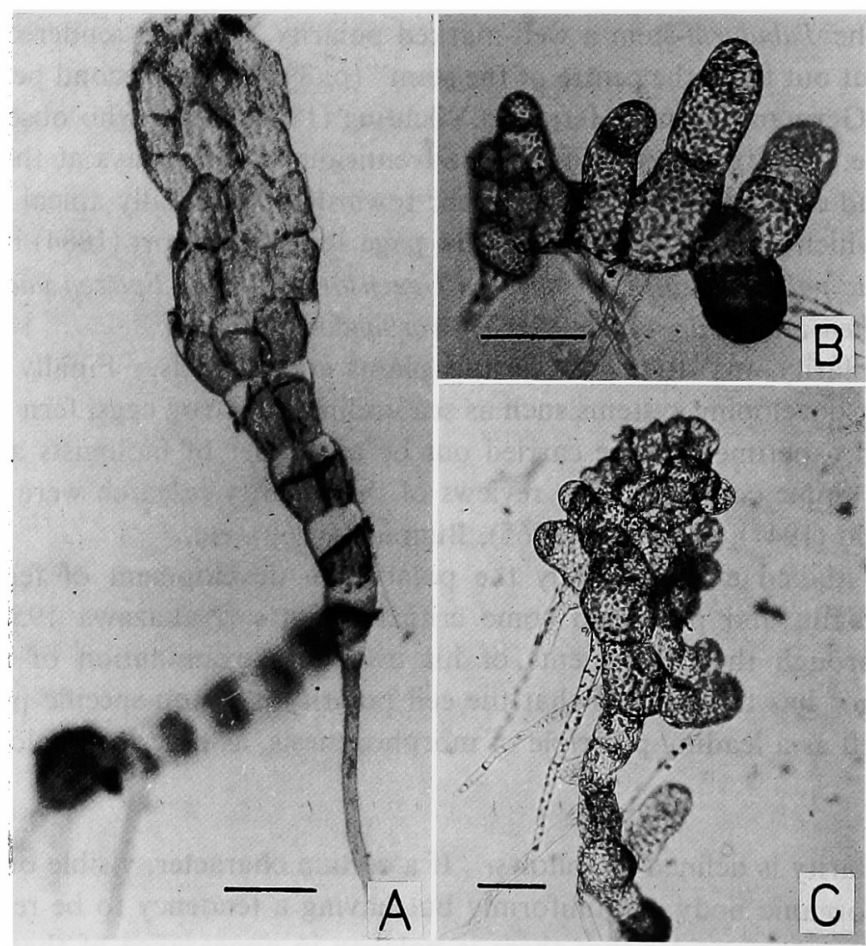

Fig. 2. Young gametophytes of ferns. A, plasmolysis by $2 \mathrm{M}$ urea solution, taking place at the apical end of cells, Polypodium hastatum. B, independent growth of cells after plasmolysis by $0.5 \mathrm{M} \mathrm{CaCl}_{2}$ in a young protonema, Pteris vittata. C, the same in a prothallus. Scale $100 \mu \mathrm{m}$.

The polarity in this sense is also seen in single cells isolated as well as combined in a tissue. Anyhow, in such a case, we call it the cell polarity. For instance, in Fucus egg the primary rhizoid is formed usually not uniformly but toward only one side of the cell, except for teratological cases unfavorable for life. In those cells combined with each other in a multicellular gametophyte of a fern (Fig. 2A), the plasmolysis takes place at the apical end of the cells 
when immersed in a hypertonic solution (Nakazawa 1961a). Similar cases are seen in many materials. Thus the cell polarity is a nonspecific property.

\section{Cell polarity in morphogenetic development}

The morphogenesis generally takes place with cell polarity, so that without polarity no morphogenesis does occur as Bünning (1948) stated, "Ohne Polarität keine Differenzierung". Positional informations as to what site of the body a certain organ is to be formed, as Wolpert (1981) says, would be impossible without polarity, as the positional singularity is determined only in a polarized space. A typical example is seen in Fucus eggs (Nakazawa 1969). They are almost completely spherical in form just after being liberated from conceptacle. That is, the egg primarily does not have polarity in morphology. If such an egg is suspended in sea water and the water is stirred irregularly so that the physical as well as chemical conditions are all unified around the egg, it is not polarized and no development does occur. But if such an apolar non-developing egg is taken out of the moving sea water and placed under still conditions, the primary rhizoid hastily begins to appear as if it had been waiting for the chance of receiving unilateral light, heat, gravity and so on. After bulging of the primary rhizoid, the egg continues development even if it is replaced to the irregularly moving sea water. This phenomenon clearly shows that the polarity is an initiator of the following morphogenesis, which proceeds according to the primary axis of the polarity even in the state of irregular movement. Thus the rhizoid is elongated toward the initial side and the apex of the embryo toward the opposite side, and the multicellular embryo develops according to the same axis of the initial polarity. It is valid, therefore, that the polarity is not only an initiator, but also a ruler of the development, i.e. it is the "logos" (leading principle) of morphogenesis.

In the spore of Equisetum arvense, things are somewhat different, but fundamentally the same. The spore is originally polarized in structure, having a latent polarity of its own. That is, a part of the cell wall is thickened in shape of a convex lense, and that part is physicochemically basophilic as it is called the basophilic center specifically stained with basic dyes such as neutral red. The primary rhizoid, in most cases, is to be formed at the basophilic center so far as the spore is germinated in the dark (Nakazawa 1958a) or under diffuse light in a state of irregular movement (Nakazawa 1956). But if the spore is cultured still under a unilateral light, the rhizoid is formed independently of the original structure but selectively on the side opposite to the light source as is well-known since the classic report of Stahl (1885). However, if it is cultured with $0.05 \%$ colchicine in dark as well as in light, it is only hypertrophied to a giant globe and does not form a rhizoid (Nakazawa 1959). That is, the spore lost polarity with colchicine and it cannot start development so far as the colchicine is not removed. Similar cases are known in Funaria spores (Bünning and Wettstein 1953), Gibasis trichoblasts, in which formation of root hair is also blocked when the cell is hypertrophied with colchicine (Yamazaki 1986), etc.

In multicellular young gametophytes of the fern, each of the component cells shows polarized plasmolysis (Fig. 2A) toward a coordinated direction. For instance, if the gametophyte of Dryopteris varia is immersed in a hypertonic solution, plasmolysis appears at the apical end of the cells. That is, each of the component cells has the polarity of its own in the same fashion toward the apex of the gametophyte at which the apical papilla is to be formed (Nakazawa 1961a). Similar phenomenon is also reported by Igura (1955). The differential plasmolysis would be attributed to regional difference in adhesion of the cell membrane to the cell wall between the basal and the apical ends of the cell. This cell polarity seems to be determined by the cellular system as a whole of the gametophyte, and the latter would be controlled by communication between cells through plasmodesms. Therefore, once the plas- 
molysis does occur, the plasmodesms are cut, so that intercellular communication is blocked and the cell polarity is lost, as a result, the cell begins to grow independently of the former polarity when replaced in an isotonic medium as in Figure 2B, C (Nakazawa 1963). Similar cases are known in isolated gametophyte cells (Ito 1962). That is, if the cells of a gametophyte of Pteris vittata are isolated by cutting then cultured with an appropriate medium, they begin to form a rhizoid and give rise to the new gametophytes, being liberated from regulation of the former organization.

As is seen in many of the similar cases, the cell polarity is on the one hand an initiator and regulator of the morphogenesis, but on the other hand it is controlled by the whole system consisting of the cell or the cells.

\section{The nature of cell polarity}

The polarity axis is sometimes artificially determined by centrifugation as in Fucus eggs. That is, if the fertilized Fucus egg is centrifuged with the force of 3,000 times gravity for 10 minutes, the intracellular organelles are clearly stratified as lipid droplets being at the centripetal end, then plastids with the nucleus, and finally the hyaloplasm toward the centrifugal end. The stratification is kept almost as it is until the primary rhizoid is formed at the centrifugal end when the egg is cultured in normal sea water of $\mathrm{pH} 8.3$ under diffuse light. It seems from this experiment as if the polarity axis was determined by localization of the organelles. But it is not always the case. In some other fucoids such as Sargassum etc. the same stratification resulted from centrifuging does not affect polarity (Nakazawa 1951). Also in trichoblasts of Gibasis, the polarity in root hair formation is not influenced by centrifuging though the intracellular elements are stratified (Nakazawa and Yamazaki 1982).

Considered from Motomura's (1949) experiments on sea urchin eggs, it seems that the cell polarity is based on the cortical layer of the cell. Therefore, if that layer be modified by centrifugation the polarity will be altered according to it. But if it be stable and not moved by a centrifugal force, the polarity will not be affected by it though organelles are stratified. Actually in sea urchin eggs (Strongvlocentrotus), the polarity cannot be determined by centrifuging with $100,000 \mathrm{~g}$ for 2 minutes despite that the organelles are stratified. But if the same centrifuging is continued for 5 minutes, the cortex of the cytoplasm is moved toward centripetal side, which later becomes the vegetal ploe (Motomura 1949). Similar cases are known in some other sea urchins and frogs. In the Fucus egg the cortical layer is supposed to be labile with centrifuging, but in Sargassum etc. it seems to be stable against the centrifugal force.

In the marine alga Bryopsis plumosa, if the filamentous thallus is transversely cut into pieces and cultured in normal sea water under diffuse light, the piece regenerates to form the new thallus at the originally apical end so far as the piece is longer than $5 \mathrm{~mm}$. If it is shorter, the whole surface of the protoplasm is separated from the cell wall probably by surface tension and a globular protoplast is obtained in the vessel of cell wall. In such a case, the regeneration takes place free from the former apicobasality (Nakazawa 1975). That is, the stability of polarity in Bryopsis is maintained by cell wall attached to the surface of protoplasm. Therefore, if the protoplasm is freed from cell wall, the former polarity is lost mechanically by rounding movement of the protoplast.

What is then the fundamental base to which the cell polarity is attributed? As to this question, it is clear that the base of polarity is not mere existence of a certain substance but it should be a certain structure of cytoplasm. Because, the cell is possible to be polarized to various orientations without changing substantial contents but by external conditions, which would affect the fine structure of cytoplasm, as is seen in Fucus eggs. Such being the case, the cell polarity must be based on a certain structure of the cortex of the cell. 
The author presumes that it should be a statistically oriented arrangement of microtubules sustained by microfilaments. The presumption is supported by the fact that the polarity is usually disturbed by colchicine which obstructs tubulin to be polymerized into microtubules (Margolis and Wilson 1977, Artvinli 1987). On the other hand, the polarity is also disturbed by cytochalasin B, which obstructs microfilaments, as in root hair formation (Yamazaki 1986). That is, it seems true that in the cortical part of the cell are arranged microtubules statistically toward the same orientation making up a framework sustained by microfilaments (Wessells et al. 1971), and it results in the cell polarity. So that, it is broken by colchicine as well as by cytochalasin. That is to say, the cell polarity, as in most of the plant cell, is considered to be attributed to a microtubule-microfilament framework system (Yamazaki 1986), and it is naturally stable so far as the cortex of the cytoplasm is adhered to the cell wall. But when it is separated by plasmolysis, injury etc. the cytoplasmic mass is rounded by surface tension of its own, and the oriented framework disappears, resulting in loss of polarity. The next appearance of the new polarity, therefore, must be followed by the new formation of cell wall or the like as the supporter of the framework. Really, the polarity determination, in protoplast, occurs always with development of cell wall, as seen in Bryopsis protoplast (Tatewaki and Nagata 1970).

\section{Summary}

1. If a certain character, visible or invisible, does occur in a cell not uniformly but having a tendency to appear toward a definite orientation, we consider that the cell has polarity in appearance of that character with respect to the polarity axis of that orientation.

2. The cell polarity is a non-specific property, appearing prior to and maintained throughout actual morphogenesis, so that, it would be an initiator and a leading principle of development. In such a sense, it can be called the "logos" of morphogenesis.

3. The cell polarity is considered to be based on an oriented framework system of microtubules supported by microfilaments in the cortical layer of the cell.

\section{References}

Allman, G. J. 1864. Report on the present state of our knowledge of the reproductive system in the Hydroida. Rep. Brit. Assoc. Adv. Sci. 351-426.

Artvinli, S. 1987. Cytoskeleton, microtubules, tubulin and colchicine: a review. Cytologia 52: 189-198.

Bloch, R. 1943. Polarity in plants. Bot. Rev. 9(5): 261-310.

- 1965. Polarity and gradients in plants: A survey. Handbuch der Pflanzenphysiol. 15(1): 234-274.

Bünning, E. 1948. Entwicklungs- und Bewegungsphysiologie der Pflanzen. Springer, Berlin. (p. 188).

- 1969. Polarität und inäquäle Teilung des pflanzlichen Protoplasten. Protoplasmatologia VIII, 9a: 1-86.

- und Wettstein, D. v. 1953. Polarität und Differenzierung an Mooskeimen. Naturwissenschaften 40: 147148.

Child, C. M. 1941. Patterns and Problems of Development. Chicago Univ. Press.

Goethe, W. v. 1827. Erläuterung zu dem aphoristischen Aufsatz "Die Natur". (Facsimile edition from Yuhodo, Tokyo, 1938).

Igura, I. 1955. Cytological and morphological studies on the gametophyte of ferns IX. The polar plasmolysis in fern prothallium. Bot. Mag. Tokyo 68: 119-124.

Ito, M. 1962. Studies on the differentiation of fern gametophytes I. Regeneration of single cells isolated from cordate gametophytes of Pteris vittata. Bot. Mag. Tokyo 75: 19-27.

Margolis, R. and Wilson, L. 1977. Addition of colchicine-tubulin complex to microtubule ends: The mechanism of substoichiometric colchicine poisoning. Proc. Natl. Acad. Sci. USA 74: 3466-3470.

Motomura, I. 1949. Artificial alteration of the embryonic axis in the centrifuged eggs of sea urchins. Sci. Rep. Tohoku Univ. 4th Ser. 18: 117-125.

Nakazawa, S. 1951. Invalid stratification to the egg polarity in Coccophora and Sargassum. Sci. Rep. Tohoku Univ. 4th Ser. 19: 73-78. 
- 1956. The latent polarity in Equisetum spore. Bot. Mag. Tokyo 69: 506-509.

- 1958a. The rhizoid point as the basophllic center of Equisetum spores. Phyton (Argentina) 10: 1-6.

- 1958b. Protoplasmic polarity as a groundwork for genic actions. Protoplasma 50: 208-211.

- 1959. Mitochondria diminution in hypertrophied Equisetum spores. Bot. Mag. Tokyo 72: 23-26.

- 1960. Nature of the protoplasmic polarity. Protoplasma 52: 274-294.

- 1961a. The polarity theory of morphogenetic fields. Sci. Rep. Tohoku Univ. 4th Ser. 27: 57-92.

- 1961b. Dynamics of morphogenetic fields. Protoplasma 58: 76-80.

- 1963. Role of the protoplasmic connections in the morphogenesis of fern gametophyte. Sci. Rep. Tohoku Univ. 4th Ser. 29: 247-255.

- 1969. Rhizoid formation of Fucus eggs under irregular rotation. Naturwissenschaften 56: 642.

- 1972. A theory on the role of polarity in cytodifferentiation. Bull. Yamagata Univ. Nat. Sci. 8: 103-112.

- 1975. Regeneration polarity in Bryopsis. Bull. Jap. Soc. Phycol. 23: 139-143.

- 1983. Cellular polarity: Proposal of the new term "intracellular polarity vector" as the component of cellular polarity. Cytologia $48: 869-872$.

- and Yamazaki, Y. 1982. Cellular polarity in root epidermis of Gibasis geniculata. Naturwissenschaften 69: 396.

Spencer, H. 1875. The Principle of Biology, Vol. II. D. Appleton and Company, New York, (p. 9).

Stahl, F. 1885. Einfluss der Beleuchtungsrichtung auf die Theilung der Equisetum-Sporen. Ber. deut. bot. Gesell. 3: 334-340.

Tatewaki, M. and Nagata, K. 1970. Surviving protoplasts in vitro and their development in Bryopsis. J. Phycol. 6: 401-403.

Vöchting, H. 1878. Über Organbildung im Pflanzenreich I. Emil Straus, Bonn.

- 1884. Ibid. II. Emil Straus, Bonn.

Wessells, N. K., Spooner, B. S., Ash, J. F., Bradley, M. O., Luduena, M. A., Taylor E. L., Wrenn, J. T. and Yamada, K. M. 1971. Microfilaments in cellular and developmental processes. Science 171: $135-143$.

Wettstein, D. v. 1965. Die Induktion und experimentelle Beeinflussung der Polarität bei Pflanzen. Handbuch der Pflanzenphysiol. 15(1): 275-330.

Wolpert, L. 1981. Positional information and pattern formation. Philosoph. Trans. Roy. Soc. London B, 295: 441-450.

Yamazaki, Y. 1986. Chemical control of cellular polarity in root hair formation in Gibasis genicluata. Cytologia 51: 763-765. 